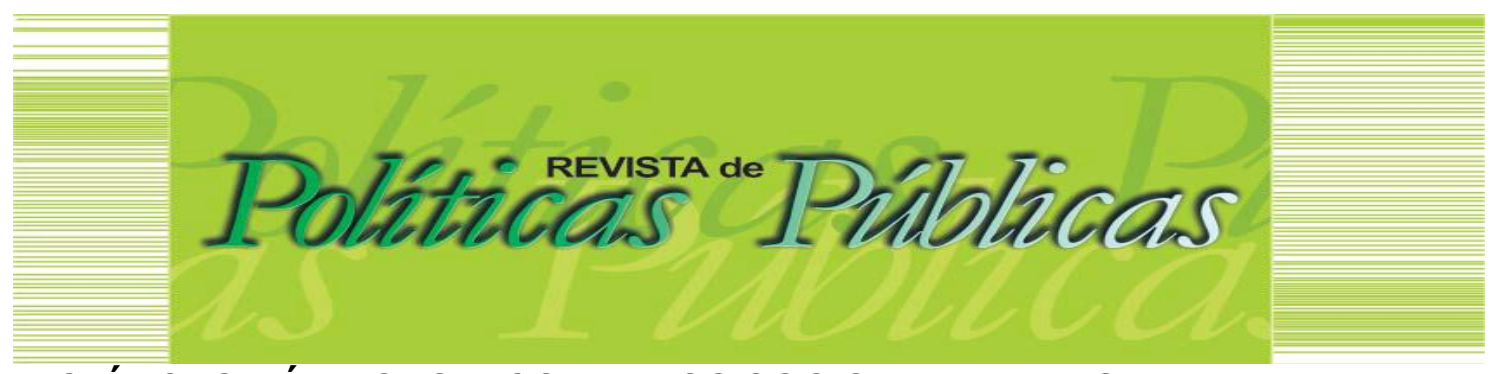

\title{
POLÍTICAS PÚBLICAS E CONFLITOS SOCIOAMBIENTAIS: problematizando 0 Seguro-Defeso da pesca artesanal ${ }^{1}$
}

\author{
Rafael Barsotti Torres² \\ Letícia de Carvalho Giannella ${ }^{3}$
}

\section{Resumo}

Considerado a principal política destinada à pesca artesanal brasileira nas últimas décadas, o Seguro-Defeso (SD) garante aos pescadores renda mínima no período de Defeso, quando ocorre interrupção forçada do trabalho. Este artigo busca realizar uma análise das contradições relacionados ao SD, abordando sua importância frente às características socioeconômicas dos pescadores, ao mesmo tempo em que problematiza a ação estatal restrita a esse benefício, entendendo-o como incapaz de fortalecer as comunidades pesqueiras nos conflitos socioambientais que enfrentam em seu dia a dia. A metodologia deste trabalho envolveu uma revisão de literatura sobre o tema, o uso dos dados do pagamento do SD e dos microdados da Pesquisa Nacional por Amostra de Domicílios Contínua (PNADC) do ano de 2018. Os resultados apontam para a importância do benefício, mas reiteram o preterimento da dimensão sociopolítica.

Palavras-chave: Seguro-Defeso. Pesca Artesanal. Conflitos socioambientais.

PUBLIC POLICIES AND SOCIO-ENVIRONMENTAL CONFLICTS: problematizing artisanal fishing insurance

\begin{abstract}
Considered the main policy intended to support the Brazilian artisanal fishing in recent decades, the Seguro-Defeso (SD) grants fishermen a minimum income during the Defeso season, when forced interruption of work occurs. This paper objective is to analyze the contradictions related to SD policy, analyzing its importance in relation to the socioeconomic characteristics of fishermen, while questioning the efficiency of the state action restricted to this benefit, understanding it as unable to strengthen fishing communities in the socio-environmental conflicts that they face. The methodology of this work involved literature review on the subject, the use of the SD payment data and the microdata of the National Continuous Household Sample Survey (PNADC) of the 2018 year. The results of this paper point to the importance of the benefit, but reiterate the neglect of the socio-political dimension.
\end{abstract}

Keywords: Seguro-Defeso. Artisanal Fishing. Socio-environmental Conflicts.

Artigo recebido em: 13/12/2019 Aprovado em: 28/04/2020 DOI: http://dx.doi.org/10.18764/2178-2865.v24n1p170-189.

\footnotetext{
1 Trabalho financiado por bolsa de pós-graduação CAPES.

2 Geógrafo. Mestre em População, Território e Estatísticas Públicas pela Escola Nacional de Ciências Estatísticas (ENCE/IBGE). Endereço: Rua André Cavalcante, 106 - Bairro de Fátima, Rio de Janeiro - RJ. CEP 20231-050. E-mail: rafaelbarsotti@uol.com.br

3 Oceanógrafa. Doutora em Geografia pela Universidade Federal Fluminense (UFF). Vínculo Empregatício: Pesquisadora em Informações Estatísticas e Geográficas da Escola Nacional de Ciências Estatísticas (ENCE/IBGE). Endereço da Universidade do Vinculo: Rua André Cavalcanti, 106, Bairro de Fátima, Rio de Janeiro/RJ. E-mail: leticiagiannella@gmail.com.
} 


\section{INTRODUÇÃO}

A pesca artesanal brasileira, assim como a pesca industrial, é um segmento da atividade pesqueira considerada profissional no Brasil. Apesar de ambas constituírem o mesmo setor produtivo, todavia, essas modalidades da pesca apresentam grandes diferenças em relação aos seus modos de produção.

No setor pesqueiro brasileiro, após longo período de prioridade quase exclusiva do Estado à pesca industrial, a pesca artesanal conseguiu, sobretudo, subsequentemente à promulgação da Constituição de 1988, se tornar alvo de políticas públicas de grande magnitude no país. Entre elas, podemos elencar o Seguro-Defeso (doravante SD), entendido como uma modalidade do SeguroDesemprego. Dessa forma, os pescadores artesanais brasileiros, estimados em pouco menos de 1 milhão pelo Ministério da Pesca e Aquicultura em 2011 (MPA, 2011), historicamente relegados pelo Estado (SILVA, 2004), passaram a se constituir como público-alvo de uma política de grande relevância.

O defeso é o período em que fica vedada a captura de determinadas espécies marinhas, fluviais e lacustres, principalmente as que despertam grande interesse comercial, de modo que seja garantida a sua adequada reprodução e recrutamento, isto é, a entrada de classes etárias mais jovens nas populações (DIAS NETO, 2017). Nesses períodos, desde 1991, a lei assegura aos pescadores artesanais que recebam um salário mínimo por mês devido à interrupção forçada do trabalho, isto é, à proibição da exploração de diversas espécies. A pesca artesanal, a ser analisada mais detalhadamente adiante, é definida legalmente como a atividade pesqueira profissional realizada de modo autônomo elou em regime de trabalho familiar, sem relações empregatícias (BRASIL, 2009).

Com a expansão do SD sob o ideário neodesenvolvimentista das últimas décadas, o que se deu a partir da promulgação da Lei n. 10.773 de 2003, compreende-se que o benefício foi transformado de um direito social constitucional à principal política para a pesca artesanal (GOULARTI FILHO, 2017). Esta transformação, entretanto, apesar de representar para os pescadores uma importante fonte de renda, se mostrou insuficiente para lidar com as questões e conflitos socioambientais ocorridos entre os pescadores e uma série de atividades, empreendimentos e processos, tais como a urbanização, a especulação imobiliária, as atividades de extração e refino de petróleo, as atividades portuárias e a pesca industrial, todas elas incentivadas pelo Estado e com presença pronunciada no período neodesenvolvimentista do capitalismo no Brasil. 
Dessa maneira, o objetivo deste artigo é analisar as contradições que envolvem o SeguroDefeso da pesca artesanal, enfatizando a importância do benefício frente às condições socioeconômicas dos pescadores e, simultaneamente, problematizando-o enquanto a principal, se não única, ação estatal de grande magnitude dirigida à categoria. Assim, serão colocadas para o debate dimensões para além da monetária, como a sociopolítica e a estrutural / produtiva, que, em nossa perspectiva, evidenciam os limites do SD no sentido do fortalecimento dos pescadores artesanais frente aos conflitos socioambientais associados ao neodesenvolvimentismo brasileiro.

Para a realização deste trabalho, foi efetuada uma revisão de literatura sobre a pesca artesanal, suas condições socioeconômicas e os conflitos socioambientais que a envolvem, assim como sobre o SD, as políticas públicas voltadas à atividade pesqueira e o neodesenvolvimentismo brasileiro. Além disso, esta pesquisa envolveu o tratamento e análise dos dados do pagamento do SD do ano de 2018, disponibilizados pelo Instituo Nacional de Seguridade Social (INSS) no portal de "Dados Abertos", buscando dimensionar quantitativamente a significância da renda aferida aos pescadores através do programa. Ainda, foram utilizados os microdados da Pesquisa Nacional por Amostra de Domicílios Contínua (PNADC) anual de 2018 com o objetivo de estimar alguns aspectos socioeconômicos dos pescadores artesanais brasileiros. Na PNADC, foi utilizada a "visita 1", dada sua centralidade nas condições socioeconômicas dos entrevistados. Na base de dados da pesquisa, foi realizada a seleção e recorte dos pescadores artesanais brasileiros através das variáveis "Código da ocupação", a qual foi selecionada a resposta "pescador", e "posição na ocupação", na qual, baseada na lei que regulamenta a atividade (BRASIL, 2009), foram selecionados os que trabalhavam por "conta própria" (autônomos) ou eram "trabalhadores familiares não remunerados" (Regime de economia familiar). O tratamento dos dados foi realizado no software estatístico R-Studio versão 1.2.5001.

\section{DESENVOLVIMENTO}

Nesse segmento do artigo, serão abordados, primeiramente, as características do modo de produção da pesca artesanal, sua importância dentre o movimento ambiental brasileiro, e os conflitos socioambientais resultantes dos embates entre a pesca artesanal e outras atividades, como a pesca industrial, cujas práticas espaciais são incompatíveis com a pesca artesanal.

Em seguida, será analisado brevemente o histórico da gestão e das políticas públicas direcionadas ao setor pesqueiro e à pesca artesanal no século $\mathrm{XX}$, ressaltando o seu caráter militar $\mathrm{e}$ desenvolvimentista. Consideramos que tais políticas fomentaram diretamente o surgimento de diversos conflitos socioambientais. No período mais recente, todavia, este processo ganha novos contornos a partir do neodesenvolvimentismo, apoiado nas tentativas de conciliação entre crescimento econômico, 
sustentabilidade e proteção social. Evidenciar-se-á de que maneira essa perspectiva políticoeconômica está representada no novo desenho do SD a partir de 2003 e, mais recentemente, como essa política está sendo desconstruída na conjuntura brasileira atual, o que aponta para o aumento da precarização das condições de vida dos pescadores artesanais.

Nesse sentido, serão analisados, por último, os dados do SD do ano de 2018 e da PNADC do mesmo ano, abordando, por um lado, a importância do benefício para a pesca artesanal e, por outro lado, suas limitações enquanto política pública unidimensional, com atuação somente no aspecto monetário. Assim, serão analisadas algumas dimensões cruciais para os pescadores artesanais brasileiros não contempladas nesta política pública.

2.1 Pesca artesanal: modo de produção, características e conflitos socioambientais

A definição da categoria pesca artesanal que vigora atualmente no Brasil foi instituída pela Política Nacional de Desenvolvimento Sustentável da Aquicultura e da Pesca, Lei ñ 11.959 de 29 de Junho de 2009, que define como pesca artesanal a

[...] praticada diretamente por pescador profissional, de forma autônoma ou em regime de economia familiar, com meios de produção próprios ou mediante contrato de parceria, desembarcado, podendo utilizar embarcações de pequeno porte; (BRASIL, 2009, art $8^{\circ}$, Inc. I).

Inscrita em lei pela primeira vez em 2009, a definição legal da atividade pesqueira artesanal foi um importante elemento para a garantia dos direitos trabalhistas da categoria. Entretanto, pesquisadores que atuam na área propõem definições mais detalhadas sobre o segmento. Diegues $(1983,2004)$ define o modo de produção da pesca artesanal como pequena produção mercantil, onde a venda para o mercado já se mostra central no processo produtivo - apesar de este ainda ser fonte de subsistência fundamental para os pescadores e suas famílias (DIAS NETO, 2010) -; a mão de obra familiar já não se torna imprescindível; a organização do trabalho encontra algumas funções especializadas e hierarquias laborais pré-definidas; e a remuneração ocorre pelo sistema de partilha ou quinhão da produção. Além disso, o trabalho é realizado de forma autônoma, de forma individual ou, mais comum, em relações de parceria; a tecnologia utilizada é marcada pelo baixo poder de predação; e os instrumentos de produção são de propriedade familiar ou individual e seu emprego ainda é muito dependente do conhecimento tradicional dos pescadores (MOURA, 2017).

Não obstante, é constatado no Brasil uma grande diversidade na atividade pesqueira, podendo esta ter caráter marítimo, fluvial ou lacustre, variantes que engendram uma profusão de divisões internas, a partir das características próprias de cada pescaria. Da mesma forma, os sujeitos e 
práticas envolvidos nestas atividades englobam uma gama com enorme diversidade, onde se inserem caiçaras, ribeirinhos, pescadores, marisqueiros, catadores-de-caranguejo, entre outros (SILVA, 2015), estabelecidos em meios extremamente distintos. Os contrastes e diferenças, em um país com as dimensões do Brasil, são enormes.

Associado a essa diversidade, há também os ciclos anuais da pesca, diferindo por região e espécie alvo da atividade pesqueira. Estes ciclos impõem regimes diferenciados a seus respectivos trabalhadores - inclusive ao embasar as decisões do IBAMA, órgão ambiental responsável pela definição do calendário de defeso - e fazem com que estes grupos tenham o ápice de seu trabalho e produção em diferentes momentos, apresentando grande variação de pescado produzido e, portanto, de rendimento ao longo dos meses e estações do ano (KANT DE LIMA, PEREIRA, 1997; DIAS NETO, 2010).

Considerada uma forma de pesca de pequena escala e com baixa capacidade de deslocamento, a pesca artesanal se desenvolveu ao longo dos séculos em estreitas relações, quase metabólicas, com o meio em que viviam os pescadores. Dessa maneira, o conhecimento das características das espécies e do litoral próximo às comunidades de pesca foi e ainda é elemento fundamental para a reprodução social dos pescadores, que desenvolveram ao longo de sua trajetória diferentes e complexos arcabouços de conhecimentos sobre a natureza em sua escala local, assim como estabeleceram vínculos e organizações coletivas que garantiram, ao menos até a chegada do modo de produção capitalista a seus territórios, a conservação dos recursos naturais e, mais especificamente, dos recursos pesqueiros. Frequentemente responsáveis pela criação de Unidades de Conservação, como as Reservas Extrativistas Marinhas (DIEGUES, 2008), assim como articulados em movimentos de conservação ambiental (LOBÃO, 2010), esses atores hoje são tidos como fundamentais dentro do atual movimento ambientalista brasileiro.

Apesar disso, com pouco ou nenhum acúmulo de capital, estes atores são permeados por algumas questões estruturais que os submetem à condição constante de debilidade em seu processo produtivo. Apesar do relativo alto valor do pescado no mercado, se comparado às outras formas de proteína animal e alimentos no geral, os pescadores costumam auferir baixo rendimento na venda de sua produção. Isto ocorre devido à falta de estrutura de processamento, transporte e comercialização da produção, que faz com que frequentemente a venda da produção artesanal seja feita para atravessadores ainda na beira da praia, mesmo em metrópoles e áreas próximas de grandes centros consumidores (LOBÃO, 2010). Por essa baixa remuneração do produto do trabalho, os pescadores com frequência recorrem à pluriatividade como forma de complemento de renda (PEREIRA; MOTA, 2015), seja agricultura de subsistência, artesanato, construção civil, sendo esta uma característica 
destacada da categoria, marcando ainda mais o contraste entre o seu modo de produção e o modo de produção capitalista, marcado pela especialização do trabalho e produtiva.

Apesar da grande tradicionalidade e da riqueza desta modalidade de pesca, ao longo das últimas décadas, o setor pesqueiro passou por grandes transformações no Brasil, em grande parte incentivadas e financiadas pelo Estado em seus períodos desenvolvimentistas, como se verá na próxima seção. Segmento capitalizado do setor pesqueiro, a pesca industrial teve crescimento exponencial nos últimos 50 anos, embora seus objetivos econômicos não tenham sido plenamente alcançados (CASTELLO, 2007; GOULARTI FILHO, 2017). O desenvolvimento deste segmento resultou num grave quadro de sobrepesca, em grande parte responsável pela atual crise dos recursos pesqueiros marinhos brasileiros (DIAS NETO, 2010). Este quadro vem resultando em uma série de conflitos com a pesca artesanal em diversas escalas, sendo os trabalhadores deste segmento carentes de políticas públicas e afetados por esse grave quadro de injustiça ambiental (ACSELRAD, 2010) - o grupo mais impactado por esse processo.

Mais recentemente, é preciso mencionar também os conflitos resultantes do crescimento exponencial da atividade aquícola em território nacional, principalmente no litoral brasileiro, entendido como o novo segmento de expansão do capitalismo no setor pesqueiro e com grande centralidade nas políticas recentes do Estado para o setor (RAMALHO, 2014). Em relação a esta atividade, os conflitos se dão por, além de implicar na privatização de áreas públicas para a cultura (AZEVEDO; PIERRI, 2014), haver a frequente expropriação de territórios tradicionais da pesca artesanal; supressão de vegetação, principalmente de mangue, com degradação do habitat das espécies pesqueiras; e contaminação química dos corpos hídricos por resíduos da produção aquícola.

Dessa maneira, a escassez dos recursos pesqueiros, associada também ao avanço da expansão urbana, alicerçada na especulação imobiliária, ocorrido em larga escala no território nacional, mas centrada no litoral brasileiro, foram centrais na desestruturação de comunidades pesqueiras artesanais por todo o país (ARAÚJO; SASSI; LIMA, 2014). O processo de urbanização do litoral brasileiro teve crescimento vertiginoso no período neodesenvolvimentista, intensificando problemas de um país já muito centrado em sua costa, e configurando uma série de conflitos socioambientais com os pescadores artesanais. Inicialmente, a disputa por território, com frequente remoção das famílias de pescadores, já se mostra um processo complexo, de difícil resolução. Além disso, a consequente degradação ambiental, destruição de habitats das espécies, como manguezais e foz de rios, poluição de corpos hídricos, se mostram bastante inconciliáveis com a atividade pesqueira.

Somam-se a essas ameaças empreendimentos como atividades portuárias (RIBEIRO; CASTRO, 2016) e de exploração de petróleo, que com frequência criam zonas de exclusão de pesca (FAUSTINO; FURTADO, 2013), onde os pescadores ficam proibidos de realizar seu ofício, além de ser 
muito comum a avaria de petrechos de pesca por embarcações de apoio a essas atividades. Não obstante, esses empreendimentos contribuem significativamente para a degradação ambiental na escala local, com grande potencial de contaminação química e lançamento de resíduos sólidos, e inclusive gerando riscos de acidentes de grande magnitude como o derramamento de óleo ocorrido ainda neste ano, 2019, no litoral brasileiro, cujas consequências se mostram tenebrosas para os pescadores brasileiros, principalmente da região Nordeste (UCHOA, 2019b).

Todas essas atividades, explorando ou associadas à exploração de recursos naturais $\mathrm{e}$ produção de commodities, plenamente inseridas no modo de produção capitalista e fomentadas pelo recente processo de neodesenvolvimentismo brasileiro, configuram um quadro de grandes conflitos socioambientais (ACSELRAD et al, 2012, 2014) entre as comunidades de pescadores e os sujeitos e atividades diretamente envolvidos nessas refuncionalizações do território, que não mais se interessam pela pesca artesanal como forma de reprodução socioambiental destes grupos e dos territórios onde vivem. Ao contrário, veem nela o atraso e o derradeiro suspiro de um ser rumo ao desaparecimento: 0 não-capitalista. No caso dos pescadores artesanais, estes, por suas características socioeconômicas e laborais, quase sempre se mostram os mais prejudicados e desorganizados por esses processos e atividades, o que os tornam, atualmente, uma categoria um tanto ameaçada no contexto brasileiro (LOBÃO, 2010).

\subsection{Políticas públicas, pesca e (neo)desenvolvimentismo brasileiro}

A gestão pesqueira no Brasil no século XX pode ser caracterizada por um processo com ao menos dois momentos distintos. Inicialmente, na primeira metade do século, com mais intensidade no período entre guerras (1918-1937), as políticas para a pesca brasileira, ainda dominada pela produção artesanal, foram marcadas pela militarização e disciplinarização dos pescadores, transformados, através da criação das colônias de pesca, em olhos e braços da Marinha brasileira, isto é, reserva naval do Estado (RAMALHO, 2014).

Na segunda fase das políticas pesqueiras, a pesca artesanal foi relegada dentro do rol das políticas de incentivo à produção. Dessa forma, é amplamente discutida na literatura a desestruturação da categoria, impulsionada pelos investimentos estatais na industrialização e maximização da produção no setor pesqueiro industrial e pelo descaso com a modalidade artesanal, principalmente ao longo da ditadura militar brasileira, período marcante do desenvolvimentismo brasileiro (DIEGUES, 1983; OLIVEIRA; SILVA, 2012).

Nesse período, a atividade pesqueira no Brasil foi regida pelo Decreto-Lei $n^{0}$ 221/1967 (Código de Pesca de 1967). Esta normativa consolidou o Registro Geral da Pesca (RGP), cadastro 
federal que regula as licenças de pesca no país e instrumento fundamental para a concessão de benefícios e garantia de direitos aos trabalhadores do setor. Marcado pela perspectiva desenvolvimentista do regime militar, a referida normativa pouco atentou para direitos e benefícios dos trabalhadores do mar. Ao contrário, o foco era explicitamente a concessão de isenções de impostos e abertura de linhas de crédito visando à industrialização do setor pesqueiro (DIEGUES, 1983; DIAS NETO, 2010), na tentativa de torná-lo competitivo internacionalmente. Dessa maneira, com a escolha pelo crescimento produtivo no ramo, em um período onde a economia ainda era intensamente dirigida pelo Estado, houve o desenvolvimento de um setor pesqueiro modernizado e capitalizado, a pesca industrial. Esta, no entanto, não conseguiu se tornar um setor competitivo internacionalmente, sendo ainda hoje muito dependente de uma série de subsídios do Estado (OLIVEIRA, SILVA, 2012; AZEVEDO, PIERRI, 2014).

Com o relativo insucesso da industrialização da pesca no país, o segmento adentrou uma crise estrutural entre a década de 80 e o século XXI. Com a retomada do projeto desenvolvimentista no início deste novo século, agora reconfigurado como neodesenvolvimentista, houve uma série de iniciativas do governo brasileiro voltadas ao crescimento produtivo do setor, como a criação do "Programa Nacional de Subvenção Econômica ao Preço do Óleo Diesel" para embarcações pesqueiras industriais; o "Programa Nacional de Financiamento da Ampliação e Modernização da Frota Pesqueira Nacional" (Profrota Pesqueira) (FILHO, 2017), entre outros, culminando com a inédita criação do Ministério da Pesca e Aquicultura em 2009 (AZEVEDO; PIERRI, 2014), extinto em 2015.

É preciso destacar que existe, na academia, um debate extenso sobre o conceito de (neo)desenvolvimentismo e sua aplicabilidade para analisar o cenário político-econômico brasileiro. 0 desenvolvimentismo costuma ser empregado para analisar o país a partir da política de substituição de importações levada a cabo por Getúlio Vargas nos anos 1930. Haveria, desde então, uma linha de continuidade que atravessaria o século $X X$ até o período em que se torna hegemônica no país a doutrina neoliberal, i.e., os anos 1980. Generalizando, tem-se como característica principal desse processo a busca por crescimento econômico por meio da forte intervenção do Estado na economia, principalmente promovendo a industrialização, o que se situa no campo do pensamento keynesiano (BRESSER-PEREIRA; THEUER, 2012).

A literatura indica que o desenvolvimento do regime de acumulação capitalista neoliberal no Brasil, que se deu a partir dos anos 1980, teria sofrido certa descontinuidade com a chegada ao poder do Partido dos Trabalhadores, em 2003. Os governos petistas (2003-2016) teriam implementado um projeto político-econômico que se aproximaria de uma perspectiva desenvolvimentista, caracterizando o que se costuma denominar como neodesenvolvimentismo (MILANEZ; SANTOS, 2014). Todavia, trata-se, neste caso, de um projeto pautado na exploração dos recursos naturais - 
associada ao ciclo global das commodities - e no desenvolvimento de infraestruturas vinculadas a este processo, aproximando as práticas político-econômicas do período de processos que autores latinoamericanos denominam como neoextrativismo (GUDYNAS, 2012) ou era do consenso das commodities (SVAMPA, 2012), entre outros. Segundo Souza e Pereira (2014, p.310), o neodesenvolvimentismo é

[...] um projeto que reivindica para si, além da abertura do comércio internacional, ampliação de investimento privado na infraestrutura e preocupação com a estabilidade macroeconômica, um lugar mais apropriado para o debate de aspectos essenciais da nossa proteção social e para o exercício da cidadania. Neste caso, com a ampliação de canais de participação social, com 0 alargamento da cobertura para riscos relacionados à perda da capacidade de trabalho e com a garantia de renda à população em situação de extrema pobreza.

Nessa nova fase do regime de acumulação capitalista brasileiro, o discurso ambiental e 0 social foram integrados à retórica econômico/produtiva do capital, estabelecendo ambiguidades, contradições e novas formas discursivas de expansão do capitalismo, compostas por diversos termos de difícil definição como "sustentabilidade", "desenvolvimento sustentável", "responsabilidade socioambiental" etc, apesar dos conflitos socioambientais apresentarem crescimento significativo no período (ACSELRAD et. al, 2012).

Dessa maneira, o SD, marcado pelo ideário dessa nova fase do capitalismo no Brasil e pelos elementos que a compõem, conforme sua reconfiguração como política setorial a partir de 2003, foi reorganizado e impulsionado com o objetivo de auxiliar financeiramente os grupos de pescadores artesanais, garantindo a eles uma renda mínima, como dissemos, nos períodos de defeso. Apesar de se configurar como importante instrumento de proteção social, entretanto, essa política se mostrou uma medida paliativa frente à desestruturação da categoria gerada pelas implicações do modelo neodesenvolvimentista, podendo ser entendida ainda como recurso para a construção de consentimento dessa população a fim de assegurar a viabilidade do projeto de expansão capitalista no país, responsável pelo acirramento dos conflitos ambientais em escala nacional.

Assim, é possível considerar que o SD, reconfigurado a partir de 2003, representa com clareza as contradições e ambiguidades do período neodesenvolvimentista brasileiro, pautado, ao mesmo tempo, no crescimento econômico associado ao ciclo das commodities e na construção de políticas conciliatórias voltadas à proteção ambiental e social, como será abordado adiante.

\subsection{O Seguro-Defeso e a pesca artesanal brasileira}

Integrada à legislação e regulamentada somente em finais do século $X X$, a pesca artesanal se manteve por muito tempo sem definição legal no Brasil. Associada a essa ausência de 
uma definição legal, até 1991, os pescadores profissionais artesanais não possuíam benefícios trabalhistas ou previdenciários especiais direcionados ao segmento, e nem recebiam o chamado Seguro-Defeso (SILVA, 2015). O SD constitui-se como uma categoria do Seguro-Desemprego previsto no artigo $7^{\circ}$ da Constituição Federal de 1988 - voltada aos pescadores artesanais, sendo garantido enquanto benefício integrante da seguridade social (BRASIL, 1988). A modalidade foi implementada a partir do entendimento de que a condição dos pescadores artesanais nos períodos de defeso se equiparava ao desemprego involuntário, caso em que se justifica a concessão do benefício.

O SD foi criado efetivamente pela lei federal $n^{0} 8.287 / 91$, e teve sua implementação iniciada já no ano de 1992. A concepção do projeto de lei objetivava garantir aos pescadores renda mínima nos períodos de interrupção forçada do trabalho, da mesma forma que dar solidez às medidas de defeso, existentes desde pelo menos 1983 (SILVA, 2015). De tal maneira, o SD já carregava em si discurso que buscava integrar a perspectiva social e ambiental na busca de um suposto uso racional dos recursos naturais, porém ainda no contexto de um Estado neoliberal.

A normativa que criou o SD foi substituída em 2003 - primeiro ano do governo Lula, marcado por mudanças na concepção da relação Estado-economia em direção a uma perspectiva neodesenvolvimentista - pela Lei $n^{0} 10.779 / 03$, que vigora atualmente, sendo modificada indiretamente pela Lei $n^{0} 11.959$, de 2009, que expandiu o público-alvo do SD; e, mais recentemente, pela Lei $n^{0}$ 13.134, de 2015, criada já no período de desconstrução do modelo neodesenvolvimentista. Inicialmente, a Lei 8.287/91 definiu que o benefício seria pago aos pescadores artesanais que, cadastrados no RGP, comprovassem ininterrupto trabalho na atividade laboral há pelo menos três (3) anos; exercessem a atividade em regime de economia familiar ou individualmente, desde que de forma artesanal; e fossem contribuintes da Previdência Social (SILVA, 2015). Segundo a mesma legislação, o defeso, as espécies, o período e as áreas de interrupção da pesca seriam definidos pelo Instituto Brasileiro de Meio Ambiente e Recursos Naturais Renováveis (IBAMA), definição que se mantém até os dias atuais (CAMPOS; CHAVES, 2014).

Em 2003, a Lei $n^{0}$ 10.779, que substituiu a lei de 1991 que instituía o SD, abrandou diversos pré-requisitos para a percepção do benefício, como o tempo de trabalho ininterrupto na atividade, com redução da exigência de 3 anos para apenas 1 ano. Além deste aspecto, a redação da nova lei atentou para o veto da concessão do benefício caso o trabalhador tivesse outras formas de rendimento, além da oriunda da pesca. Assim, foi definido que o pescador que recebesse o benefício não poderia dispor de fonte de renda que não da atividade pesqueira (SILVA, 2015), requisito que implica em profundo contraste com o modo de vida dos pescadores artesanais, marcado pela pluriatividade, com centralidade na pesca, mas dependentes de outras formas de produção e fontes de renda. Segundo os dados analisados em Brasil (2017), do início do período de vigência desta lei até 
sua alteração indireta realizada pela Lei $n^{0} 11.959 / 09$, o número de beneficiários do SD passou de 113,7 mil para mais de 500 mil.

Criada em 2009, a Lei $n^{0} 11.959$ estabeleceu princípios, conceitos e medidas voltadas para o planejamento e execução da atividade pesqueira e da aquicultura. Como afirmado anteriormente, a lei apresentou novas definições da categoria pesqueira artesanal e das características do ofício, enquadrando outras funções e atividades laborais inseridas nas etapas não produtivas da cadeia na modalidade. Ao mesmo tempo, a Secretaria Especial de Pesca e Aquicultura, ligada diretamente à presidência da república, foi transformada em Ministério da Pesca e Aquicultura (MPA) pela Lei $n^{0} 11.958 / 09$. A nova lei e a criação do inédito ministério mostravam ao país a prioridade que se daria ao setor pesqueiro, ou pelo menos a alguns ramos deste, naquela conjuntura neodesenvolvimentista (AZEVEDO; PIERRI, 2014).

Com a expansão do conceito de pesca artesanal, houve também um acréscimo do número de possíveis beneficiários do programa de SD, incluindo uma série de trabalhadores não relacionados diretamente à etapa produtiva da cadeia da pesca, como tecedores de rede, artesãos, produtores e reparadores de petrechos, e ao processamento do pescado, tarefas que com frequência incluem parentes e cônjuges de pescadores. Esta inclusão representou de fato um ganho importante para todo este setor produtivo, beneficiando, de forma ainda mais abrangente, os seus trabalhadores nos períodos de interrupção forçada do trabalho.

Dessa maneira, analisando os dados constantes em Brasil (2017), nos primeiros anos do programa (1991-1992), o número de beneficiários do Seguro-Defeso foi pequeno se comparado ao total de pescadores do país, tendo ocorrido, no entanto, um crescimento exponencial, principalmente ao longo da primeira década dos anos 2000. De acordo com os dados utilizados no referido trabalho, os valores foram de 2,7 mil em 1992, para 29,1 mil em 1997 e 92 mil em 2002. De 2003 em diante, regidos pela Lei $n^{0} 10.779$, os beneficiários foram de 113 para mais de 500 mil em 2009. Após a promulgação da Lei $n^{0} 11.959 / 09$, o crescimento no número de beneficiários se mostrou contínuo até 2012, indo de aproximadamente 550 mil para quase 970 mil em 2012, terminando em 2015 com cerca de 736 mil (BRASIL, 2017) (Gráfico 1). É impossível implicar causalidade nesse fenômeno, contudo, as reduções das exigências para aptidão ao benefício e a nova definição expandida de pesca artesanal, amparados pelo ideário desenvolvimentista dos governos petistas, demonstram ser elementos importantes para o aumento do volume de beneficiários. 
Gráfico 1 - Beneficiários do Sequro-Defeso entre 1992-2015.

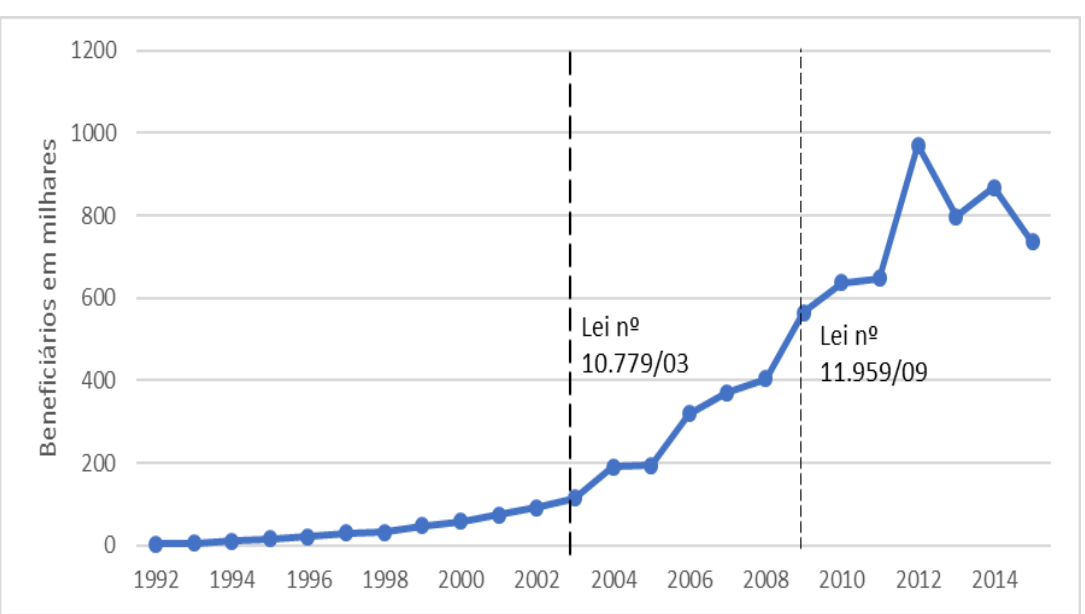

Fonte: Ministério do Trabalho e Emprego (apud BRASIL, 2017).

Por essa razão, o entendimento deste trabalho é que $0 \mathrm{SD}$, inicialmente fundamentado enquanto direito social previsto na constituição, foi elevado à categoria de política setorial, carregada do ideário neodesenvolvimentista característico dos governos do Partido dos Trabalhadores, se tornando quase que uma política única voltada ao segmento. Dessa forma, o SD, embasado na concepção das políticas de transferência de renda como forma de combate à desigualdade, se consolidou como política central voltada ao segmento da pesca artesanal.

Reforçam essa percepção o fato de demais programas destinados à categoria executados no mesmo período, principalmente os que carregavam o ideário da inclusão produtiva, como 0 PRONAF-Pesca, uma vertente do Programa Nacional de Fortalecimento da Agricultura Familiar, apresentarem exigências que praticamente inviabilizaram o acesso à grande maioria dos trabalhadores do segmento, dificuldades percebidas por pesquisadores em diversas comunidades pesqueiras (SILVA, 2015). Dessa maneira, corrobora com essa hipótese o fato de nenhuma outra política direcionada à pesca artesanal alcançar a magnitude e efetividade na vida dos pescadores artesanais das mais diferentes características e regiões do país como o SD conseguiu, garantindo de fato rendimento monetário expressivo frente ao perfil socioeconômico dos pescadores. Apontam nesta perspectiva diversos estudos de caso realizados em regiões como a Amazônia (SCHMITZ; MOTA; PEREIRA, 2013; PEREIRA; MOTA, 2015), Nordeste (MENDONÇA; PEREIRA, 2012; REZENDE; OLIVEIRA, 2015) e Sul/Sudeste do país (BECKER, 2013; MENDONÇA, 2015). Nestes estudos de caso, é realçado como o rendimento oriundo do SD é usado para as mais diferentes finalidades, tanto no investimento em insumos e equipamentos de pesca, quanto para gastos diversos dos pescadores e suas famílias, como alimentação, saúde, utensílios e infraestrutura domiciliar.

Analisando os dados do pagamento do SD no ano de 2018, o total de beneficiários registrados na base do Instituto Nacional de Seguridade Social (INSS) que o receberam foi de 685.765 
pescadores, número significativamente menor que em anos anteriores (DIAS NETO, 2017). Os pescadores artesanais beneficiados em 2018 estavam concentrados nas regiões Norte e Nordeste do país, representando respectivamente $38 \%$ e $49 \%$ do total de beneficiários do programa. O Sudeste, Sul e Centro-Oeste tiveram, respectivamente, apenas 6,8\%, 3,8\% e 2\% do total (Tabela 1).

Tabela 1 - Pescadores artesanais que receberam o SD por Macrorregião, Brasil: 2018.

\begin{tabular}{ccc}
\hline Macrorregião & Beneficiários & Porcentagem \\
\hline Norte & 261.545 & 38,10 \\
Nordeste & 336.970 & 49,10 \\
Sudeste & 46.791 & 6,80 \\
Sul & 26.247 & 3,80 \\
Centro-Oeste & 14.212 & 2,10 \\
\hline Brasil & 685.765 & 100 \\
\hline
\end{tabular}

Fonte: Instituto Nacional de Seguridade Social (INSS), dados do SD de 2018.

Em relação ao montante aferido pelos pescadores, o valor médio de cada parcela paga foi de $R \$ 950$, enquanto a média de parcelas recebidas foi de quatro (4) por pescador, número de parcelas que foi recebido por mais de $73 \%$ dos favorecidos pelo SD. Dessa maneira, o valor médio recebido pelos pescadores no ano girou em torno de $\mathrm{R} \$ 3.726,10$, valor que, se dividido pelos meses do ano, daria uma renda média mensal de $\mathrm{R} \$ 310,50$ (Tabela 2).

Tabela 2 - Parcelas e valores do SD recebidos por pescador no ano em reais, Brasil: 2018.

\begin{tabular}{c|c|c|c|c}
\hline $\begin{array}{c}\text { Parcelas } \\
\text { recebidas }\end{array}$ & $\begin{array}{c}\text { Pescadores } \\
\text { beneficiados }\end{array}$ & $\begin{array}{c}\text { Percentual de } \\
\text { beneficiários (\%) }\end{array}$ & $\begin{array}{c}\text { Renda média mensal } \\
(\mathrm{R} \$)\end{array}$ & $\begin{array}{c}\text { Renda média } \\
\text { anual (R\$) }\end{array}$ \\
\hline 1 & 4.669 & 0,7 & 79,00 & 948,00 \\
2 & 31.607 & 4,6 & 158,48 & $1.901,77$ \\
3 & 105.009 & 15,3 & 236,92 & $2.843,11$ \\
4 & 502.830 & 73,3 & 317,68 & $3.812,18$ \\
5 & 13.284 & 1,9 & 365,76 & $4.389,07$ \\
6 & 4.676 & 0,7 & 471,91 & $5.662,99$ \\
$7+$ & 23.690 & 3,4 & - & - \\
\hline Total & 685.765 & 100,00 & 310,50 & $3.726,10$ \\
\hline
\end{tabular}

Fonte: INSS, dados do SD de 2018.

Esses valores se mostram bastante significativos se comparados tanto à renda média dos pescadores artesanais encontrada a partir do tratamento dos dados da PNADC, cerca de $\mathrm{R} \$ 545$ mensais oriundos da pesca, $\mathrm{R} \$ 718$ aferidos de todas as fontes e $\mathrm{R} \$ 493$ de rendimento per capita, quanto de levantamentos e estudos de caso de caso realizados por pesquisadores (FUZETTI; CORREAA, 2009; MENDONÇA, 2015) que, corrigindo os valores para o ano de 2018, encontraram 
renda mensal total dos pescadores artesanais de até $R \$ 850$, quando não inferior, como a identificada por Rezende e Oliveira (2015), em cerca de R\$260 mensais.

Corroborando com os valores encontrados acima, a estimativa encontrada na PNADC anual de 2018 para as faixas de renda dos pescadores artesanais oriundos da pesca apresentou distribuição extremamente concentrada nas categorias de rendimento de até meio salário mínimo e entre meio e um (1) salário. O primeiro segmento conpreendeu cerca de $55 \%$ dos pescadores artesanais brasileiros, enquanto o segundo, cerca de $30 \%$ (Gráfico 2). No total, mais de $85 \%$ deste universo ganhavam até um salário mínimo mensal, valor que realça a magnitude e importância do SD enquanto política social.

Gráfico 2 - Pescadores artesanais, por faixa de renda em salários mínimos (SM) recebidos do trabalho principal, Brasil: 2018.

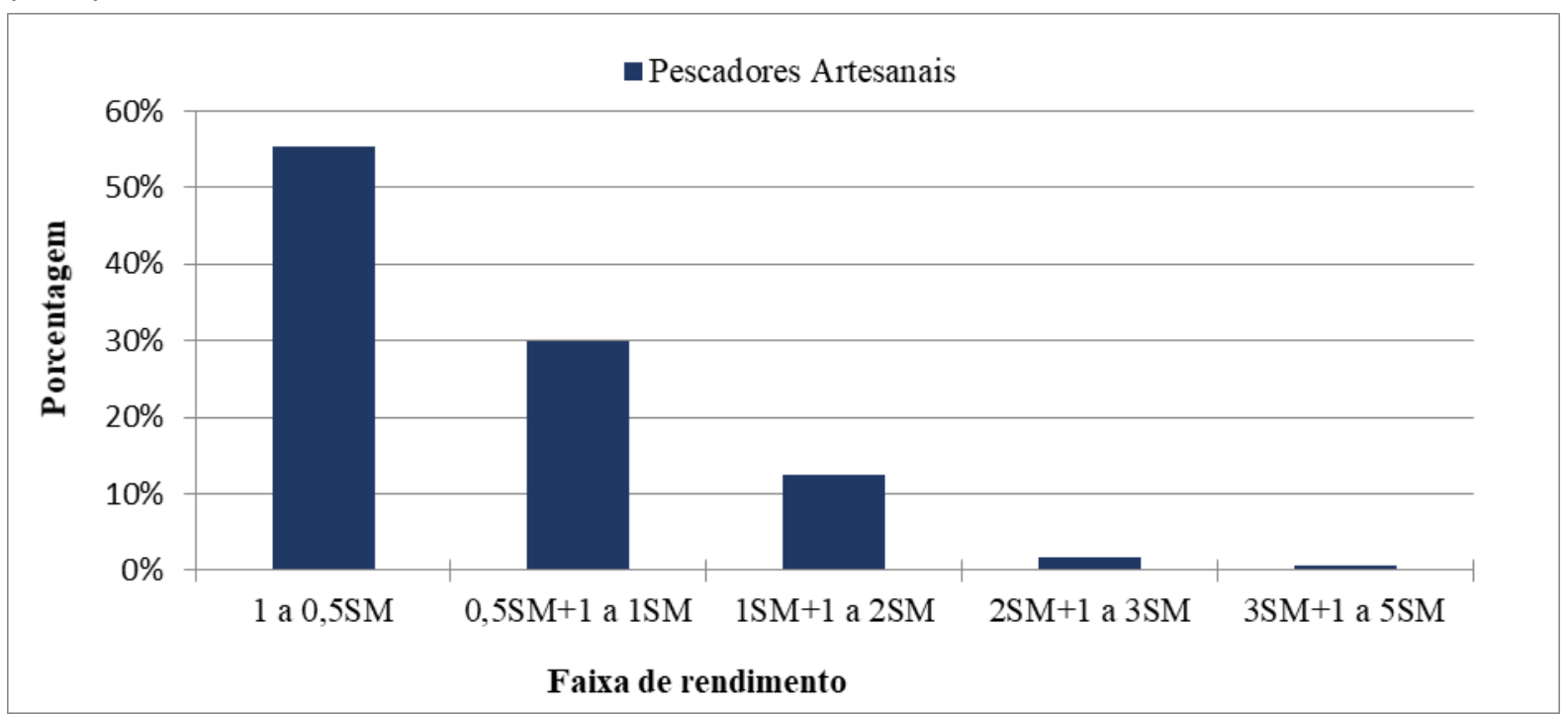

Fonte: IBGE, microdados da PNAD Contínua de 2018.

Além destes estudos de caso e da análise da PNADC, Campos e Chaves (2016) encontraram um perfil econômico muito próximo, utilizando a Pesquisa Nacional por Amostra de Domicílios (PNAD) de 2013, estimando o rendimento dos pescadores em cerca $R \$ 560$ oriundos da pesca em si, $R \$ 684$ de todas as fontes de renda e apenas $R \$ 460$ de rendimento domiciliar per capita.

Apesar dessa importância econômica, o programa do SD, protagonista dentre as políticas voltadas à pesca artesanal, centrado no indivíduo e restrito à dimensão monetária, apresenta uma série de limitações intrínsecas a seu escopo. Na forma como o programa é desenhado, aspectos relacionados às dimensões estruturais da atividade pesqueira, como petrechos e equipamentos de pesca, de processamento, transporte e escoamento da produção, que muitas vezes poderiam ser resolvidos coletivamente, com políticas direcionadas às comunidades e associações de pescadores, são relegados. Além disso, aspetos estruturais elementares para a reprodução social dos pescadores artesanais, como regularização fundiária, infraestrutura domiciliar, acesso a serviços e equipamentos 
públicos, são também preteridos dentro deste desígnio neodesenvolvimentista. Igualmente, a dimensão ambiental, fundamental para trabalhadores que vivem da extração de recursos naturais com relativo baixo impacto ambiental, se mostra muito depreciada nesse período, abordada por políticas pouco desenvolvidas e com frequência ineficazes na manutenção dos estoques pesqueiros, sendo o próprio defeso - da maneira como é implementado, com pouca fiscalização e quase nenhum monitoramento uma medida muitas vezes considerada paliativa (DIAS NETO, 2017).

Da mesma forma, a dimensão sociopolítica dos trabalhadores da pesca artesanal, envolvendo tanto quesitos como a instrução formal e 0 aspecto educacional de forma abrangente entendido aqui não apenas como o nível de escolaridade e o tempo de estudo em instituições de ensino, mas também a partir da valorização e construção do conhecimento tradicional, assim como as formas de sociabilidade e organização coletiva das comunidades de pesca artesanal -; a composição racial do segmento, dominado por trabalhadores pardos e pretos (SILVA, 2015); e o próprio aspecto econômico; quanto a elementos como a propriedade da terra, com ausência de titulação em enorme percentual da categoria, irá configurar relações de poder extremamente desiguais.

Dessa maneira, os conflitos socioambientais entre os pescadores e os diversos sujeitos que exploram ou desejam explorar seus territórios tradicionais se dão através de relações com geometrias de poder extremamente desiguais (MASSEY, 2000), dado que meramente 0 aspecto monetário, no caso do SD - resumido a alguns salários mínimos por ano de benefício aos pescadores - pouco representa para os pescadores nestas disputas. Esta dimensão sociopolítica, determinante no campo de forças que se configura a sociedade capitalista, é excluída não apenas do escopo do SD, mas de qualquer forma de política pública construída e implementada no período neodesenvolvimentista no âmbito da atividade pesqueira artesanal.

Logo, apesar de os pescadores contarem com garantia de rendimento em determinados períodos do ano - usualmente maior do que auferem mensalmente na faina pesqueira - diversas dimensões e aspectos importantes para sua resistência e reprodução social no seio do capitalismo de mercado são relegados pelo poder público, comprometendo seriamente a permanência da categoria enquanto populações tradicionais e importantes produtores de alimentos para a sociedade brasileira.

Por outro lado, é preciso reforçar a importância da política e as tentativas de desmonte a que a mesma vem sendo submetida. Mesmo evidenciada a importância socioeconômica do SD para a pesca artesanal, o constante aumento do número de beneficiários fez com que nos últimos anos 0 programa fosse marcado por acusações de fraude (CAMPOS; CHAVES, 2014; DIAS NETO, 2017; BRASIL, 2017). Investigações e auditorias voltadas ao exame da realização e manutenção do programa, que passam pelo cadastro no RGP, pela averiguação dos controles internos do extinto Ministério do Trabalho e Emprego, e pelos pagamentos feitos aos pescadores, encontraram fraudes e 
pagamentos indevidos, que não apresentavam, porém, magnitude que inviabilizasse ou justificasse a interrupção do programa (TCU, 2015; 2016). Mesmo assim, fundada na retórica do combate às fraudes, o cadastro de pescador profissional (RGP), pré-requisito para o acesso ao SD, até hoje passa por uma reformulação que impede a emissão de novas licenças, apenas concedendo outras provisórias, com enorme grau de burocracia e dificuldade aos pescadores artesanais.

Sob a ótica do SD, a gama de atividades laborais acrescidas à categoria pesca artesanal pela Lei no 11.959/09 resultou na necessidade de verificação e fiscalização dos novos indivíduos cadastrados no programa, já que esses de fato deviam estar ocupados nas funções relacionadas à atividade pesqueira artesanal em que afirmavam labutar. Pelo caráter de informalidade dos ofícios e relações de trabalho no setor, todavia, estas atividades laborais são exercidas quase sempre de forma autônoma, sem vínculos empregatícios e com poucos registros dos serviços prestados. De tal maneira, a análise da veracidade das declarações destes beneficiários junto ao RGP se mostra extremamente difícil, ainda mais em se tratando de um registro nacional que abarca um país com as dimensões e distintas características regionais que tem o Brasil.

Esses trabalhadores, detentores dos mesmos direitos trabalhistas, sociais, previdenciários, e assim, com direito ao Seguro-Desemprego por interrupção involuntária garantido pela constituição, não poderiam ser, entretanto, excluídos do programa do SD, embora o tenham sido. Apesar de admitidos enquanto beneficiários tardiamente, apenas em 2009, estes trabalhadores logo perderam o acesso ao programa, em vista da promulgação da Lei n 13.134/2015. Aprovada em 2015, esta normativa modificou a Lei n 10.779 de 2003, dispondo que, apesar da definição dada à "atividade pesqueira artesanal" na Lei $n^{0} 11.959 / 09$, o SD não seria "extensível às atividades de apoio à pesca nem aos familiares do pescador profissional que não satisfaçam os requisitos e as condições estabelecidos nesta Lei" (BRASIL, 2015). Isto é, a redação excluiu novamente todas as atividades de caráter não produtivo ligadas à atividade pesqueira artesanal.

Mais recentemente, na atual conjuntura de neoliberalização radical adotada pelo governo brasileiro, após impeachment de Dilma Rousseff em 2016, com desmonte das políticas públicas e programas sociais, aprofundamento de princípios individualistas e ruptura com os sistemas de solidariedade sistêmica (SANTANA, 2019), o SD tem sofrido mais ameaças e ataques. Embasados nos mesmos discursos de fraudes em massa no cadastro do benefício, retórica generalista que, historicamente, serviu à desconstrução dos direitos sociais, esses ataques, no caso do SD, baseiam-se em dois pilares argumentativos: i) pescadores artesanais que têm outras atividades remuneradas e assim não poderiam receber o Seguro, como definido pela Lei $n^{0} 10.779 / 03$ e reiterado na $n^{0}$ 13.134/15; ii) pessoas que não trabalham na pesca que recebem o benefício. Em abril de 2019, se utilizando desse arcabouço discursivo, o atual Presidente da República emitiu uma declaração num 
popular sítio de streaming - sem nenhuma explicação sobre o método pelo qual se estimou o referido percentual - afirmando que $65 \%$ dos benefícios pagos eram fraudulentos, situação denominada por ele como "a festa do defeso" (VILELA, 2019).

\section{CONCLUSÃO}

O Seguro-Defeso, entendido como política elaborada no bojo da redemocratização e expandida no auge do neodesenvolvimentismo brasileiro das décadas passadas, se apresenta enquanto mecanismo estatal de correção dos "vícios" e "defeitos" criados pelo mercado, em grande parte gerados pelo fomento do próprio Estado (SOUSA; PEREIRA, 2014). Esta perspectiva se mostra ainda mais factual no setor pesqueiro nacional, marcado pela industrialização forçada, dirigida pelos grandes incentivos dos governos brasileiros nos séculos XX e XXI.

Apesar disso, não pode ser relevada a importância que o auxilio monetário realizado pelo seguro tem para os pescadores artesanais do país, atestado pelos estudos de caso, pela análise dos dados da PNADC e do SD, e facilmente perceptível em qualquer contato que se tenha com comunidades de pesca artesanal do país. Dessa forma, a atual conjuntura de desconstrução dos pilares de proteção social põe em xeque a política pública que, com todas suas limitações estruturais, mais teve efetividade na vida e reprodução social dos pescadores artesanais brasileiros nas últimas décadas e, provavelmente, em toda história do Brasil.

Além disso, o derramamento de óleo de largas proporções que aconteceu recentemente no litoral brasileiro, afetando principalmente a costa da região Nordeste, - agravado pelo descaso e inação do governo brasileiro (GRAGNANI, 2019) - cuja grande parte dos desdobramentos ainda está por vir, aponta para um cenário próximo de grande ameaça à pesca artesanal. Com contaminação química e física do pescado; inviabilidade produtiva, econômica e social da atividade; incapacidade de comercialização da produção por temor da contaminação; redução do estoques pesqueiros; além dos evidentes prejuízos possivelmente causados à saúde dos pescadores que tiverem contato com o óleo, as comunidades de pesca artesanal brasileiras já sofrem consequências imediatas deste crime ambiental (UCHÔA, 2019a). Estas mazelas, no entanto, provavelmente se arrastarão e aprofundarão nos próximos anos, de modo que se aninham no horizonte tempos árduos para a pesca artesanal brasileira (UCHÔA, 2019b). Estas circunstâncias, somadas ao aprofundamento do neoliberalismo brasileiro nos anos recentes, implicam em uma importância ainda maior do SD em um momento de ameaças e incertezas sobre a continuidade do programa.

Apesar disso, é fundamental que se tenha no horizonte de luta e articulação política, a necessidade de integração das dimensões estrutural e sociopolítica nas políticas públicas, de modo a 
fortalecer os sujeitos e vínculos sociais da pesca artesanal em seus embates e conflitos socioambientais diários, travados coletivamente, com esta série de atores e instituições que, impulsionados pelo período neodesenvolvimentista, compõem atualmente o modelo capitalista brasileiro e que ameaçam constantemente a reprodução dos pescadores artesanais.

\section{REFERÊNCIAS}

ACSELRAD, H. Ambientalização das lutas sociais: o caso do movimento por justiça ambiental.

Estudos Avançados, 24 (68), p. 103-119, 2010.

Disputas cognitivas e exercício da capacidade crítica: o caso dos conflitos ambientais no Brasil. Sociologias, v. 15, p. 84-115, 2014.

ACSELRAD, H. et al. Desigualdade ambiental e acumulação por espoliação: o que está em jogo na questão ambiental? E-cadernos CES, p. 164-183, 2012.

ARAÚJO, I. X.; SASSI, R.; LIMA, E. R. V. Pescadores artesanais e pressão imobiliária urbana: Qual o destino dessas comunidades tradicionais? Revista de Gestão Costeira Integrada, v. 14, n. 3, p. 429446, set. 2014.

AZEVEDO, N. T.; PIERRI, N. A política pesqueira no Brasil (2003-2011): a escolha pelo crescimento produtivo e o lugar da pesca artesanal. Revista Desenvolvimento e Meio Ambiente, Curitiba, v. 32, [s.i], p.61-80, 2014.

BECKER, A. Seguro-defeso e pescadoras artesanais: o caso do estuário da Lagoa dos Patos Boletim Científico ESMPU, Brasília, n. 41, p.45-91, jul./dez. 2013.

BRASIL. Constituição (1988). Constituição da República Federativa do Brasil. Brasília, DF: Senado Federal, 1988.

Lei $n^{0} 11.959$, de 29 de junho de 2009. Dispõe sobre a Política Nacional de Desenvolvimento Sustentável da Aquicultura e da Pesca e dá outras providências. Diário Oficial, Brasília, v. 146, n. 122, 30 jun. 2009. Seção I, p. 1-15.

Lei $n^{0} 13.134$, de 16 de junho de 2015. Altera a lei no 10.779, de 25 de novembro de 2003, que dispõe sobre o seguro-desemprego para o pescador artesanal e dá outras providências. Diário Oficial, Brasília, v. 152, n. 113, Seção 1, p. 1-2.

Relatório de avaliação da execução de programas de governo $n^{0} 70 / 2017$ - fiscalização e monitoramento para a sustentabilidade dos recursos aquícolas e pesqueiros. Brasília: CGU, 2017.

CAMPOS, A. G.; CHAVES, J. V. Seguro defeso: diagnóstico dos problemas enfrentados pelo programa. Brasília: Ipea, 2014. 74 p. ISSN: 1415-4765.

Perfil laboral dos pescadores artesanais no Brasil: insumos para o programa Seguro Defeso.

Mercado de Trabalho, n. 60, p. 63-73, abr. 2016. 
CASTELLO, J. P. Gestão sustentável dos recursos pesqueiros, isto é realmente possível?. PanAmerican Journal of Aquatic Sciences, v. 2, n. 1, p. 47-52, 2007.

DIAS NETO, J. Gestão do uso dos recursos pesqueiros marinhos no Brasil. Brasília: Ibama, 2010. Análise do seguro-desemprego do pescador artesanal e de possíveis benefícios para a gestão pesqueira. Brasília: Ibama, 2017, 120 p.

DIEGUES, A. C. Pescadores, camponeses e trabalhadores do mar. São Paulo: Ed. Àtica, 1983.

A pesca construindo sociedades: leituras em antropologia marítima e pesqueira. São Paulo: NUPAUB/USP, 2004.

Marine Protected Areas and Artisanal Fisheries in Brazil. Chennai/India: International Collective in Support of Fishworkers, 2008. 54p.

FAUSTINO, C.; FURTADO, F. Indústria do Petróleo e Conflitos Ambientais na Baía de Guanabara: o caso do Comperj. Rio de Janeiro: Dhesca, 2013.

FUZETTI, L.; CORREAA, M. F. M. Perfil e renda dos pescadores artesanais e das vilas da llha do Mel, Paraná, Brasil. Boletim do Instituto de Pesca, v. 35, p. 609-621, 2009.

GOULARTI FILHO, A. Da SUDEPE à criação da Secretaria Especial de Aquicultura e Pesca: as políticas públicas voltadas às atividades pesqueiras no brasil. Planejamento e Políticas Públicas, n. 49, jul/dez. 2017.

GRAGNANI, J. O plano para conter derrames de petróleo que não foi acionado pelo governo federal para o Nordeste. BBC News Brasil, Londres, out. 2019. Disponível em:

https://www.bbc.com/portuguese/brasil-50104828. Acesso em: 22 nov. 2019.

LOBÃO, R. Cosmologias Politicas do Neocolonialismo: como uma política pública pode se transformar em política do ressentimento. Niterói: EdUFF, 2010.

MASSEY, D. Um sentido global do lugar. In: ARANTES, A. O espaço da diferença. Campinas: Papirus, 2000. p. 177-185.

MENDONÇA, J. T. Caracterização da pesca artesanal no litoral sul de São Paulo - Brasil. Boletim do Instituto de Pesca, v. 41, p. 479-492, 2015.

MENDONÇA, J. T.; PEREIRA, A. L. C. Avaliação do Seguro-Defeso concedido aos pescadores no estado da Paraíba. In: Encontro de Ciências Sociais do Norte e Nordeste, 15, 2012, Tereseina - PI. Anais..., Teresina: ECSNN, 2012, p. 1-15.

MINISTÉRIO DA PESCA E AQUICULTURA - MPA. Boletim Estatístico da Pesca e Aquicultura 2011. Brasília: MPA, 2011.

OLIVEIRA, O. M. B. A. de; SILVA, V. L. da. O processo de industrialização do setor pesqueiro e a desestruturação da pesca artesanal no Brasil a partir do Código de Pesca de 1967. Sequência, Florianópolis, n. 65, p. 329-357, 2012. 
PEREIRA, J. A.; MOTA, D. M. De lavradores a pescadores artesanais: camponeses. Cadernos CERU, v. 26, n. 2, 2015.

RAMALHO, C. W. N. Estado, pescadores e desenvolvimento nacional. Da reserva naval à aquícola. Ruris, v. 8, n. 1, p. 31-62, mar. 2014.

REZENDE, P. C.; OLIVEIRA, I. da M. Descrição socioeconômica dos pescadores no Baixo São Francisco, Nordeste-Brasil. Revista de Desenvolvimento Econômico, Salvador, Ano XVII - Edição especial, p. 671-689, dez. 2015.

RIBEIRO, I.; CASTRO, A. C. L. Pescadores artesanais e a expansão portuária na praia do Boqueirão, Ilha de São Luís-MA. Revista de Políticas Públicas, v. 20, n. 2,p. 864-884, 2016.

SANTANA, R. N. N. Da Política Urbana: notas sobre a perda de potência do inovador discurso constitucional brasileiro. SER Social, Brasília, v. 21, n. 44, p. 94-113, jan/jun. 2019.

SCHMITZ, H.; MOTA, D. M.; PEREIRA, J. A. Pescadores artesanais e Seguro Defeso: Reflexões sobre processos de constituição de identidades numa comunidade ribeirinha da Amazônia. Revista de Antropologia (Online), v. 5, n. 1, p. 116-139, 2013.

SILVA, C. A. da. Política Pública e Território: passado e presente da efetivação de direitos dos pescadores artesanais no Brasil. Rio de Janeiro: Consequência, 2015.

SILVA, P. P. da. From common property to co-management: lessons from Brazil's first maritime extractive reserve. Marine Policy, v. 28, n. 5, p. 419-428, 2004.

SOUSA, S. M. P. S. de; PEREIRA, M. E. F. D. Pobreza e cidadania em tempos de neodesenvolvimentismo no Brasil. SER Social, Brasília, v. 16, n. 35, p. 308-326, jul.-dez./2014.

TRIBUNAL DE CONTAS DA UNIÃO (TCU). Auditoria no seguro-desemprego do pescador artesanal. Brasília: TCU, 2015.

Controles sobre os procedimentos de inscrição e manutenção da licença de pescador artesanal para recebimento do seguro-defeso. Brasília: TCU, 2016.

UCHÔA, V. 'Ninguém quer o que pescamos': o drama dos pescadores com o petróleo no litoral da Bahia. BBC News Brasil, Salvador, Out. 2019a. Disponível em:

https://www.bbc.com/portuguese/brasil-50158823. Acesso em: 20 de nov. 2019.

Danos do óleo no litoral do Nordeste vão durar décadas, dizem oceanógrafos. BBC News Brasil, Salvador, Out. 2019b. Disponível em: https://www.bbc.com/portuguese/brasil-50131560. Acesso em: 24 nov. 2019.

VILELA, P. R. Seguro-defeso tem fraude em $65 \%$ dos benefícios, diz Bolsonaro. Agência Brasil, Brasília, Abr. 2019. Disponível em: http://agenciabrasil.ebc.com.br/politica/noticia/2019-04/segurodefeso-tem-fraude-em-65-dos-beneficios-diz-bolsonaro. Acesso em: 20 nov. 2019. 